
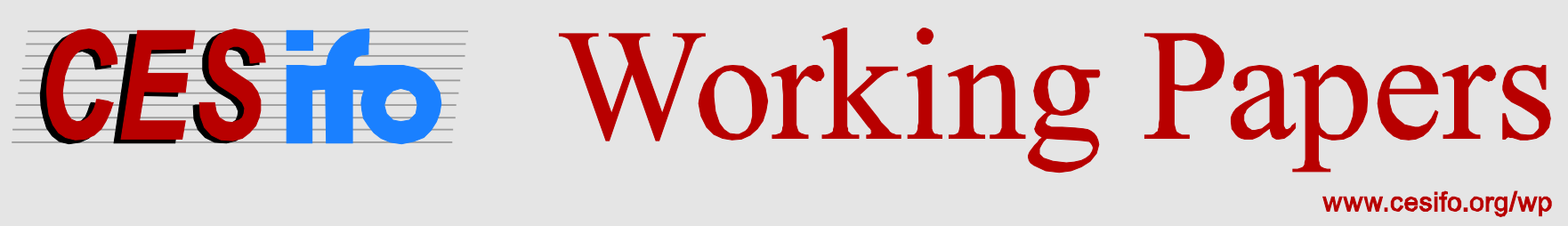

\title{
Electoral Externalities in Federations - Evidence from German Opinion Polls
}

\author{
Xenia Frei \\ Sebastian Langer \\ Robert Lehmann \\ Felix Roesel
}

CESIFO WORKING PAPER NO. 6375

CATEgory 2: PuBlic CHOICE

FEBRUARY 2017

An electronic version of the paper may be downloaded

- from the SSRN website:

- from the RePEc website:

- from the CESifo website:

WWw.SSRN.com

www.RePEc.org

www.CESifo-group.org/wp 


\title{
Electoral Externalities in Federations - Evidence from German Opinion Polls
}

\begin{abstract}
Party performance in state and federal elections is highly interdependent. Federal elections impact regional voting dynamics and vice versa (electoral externalities). We quantify the extent of simultaneous electoral externalities between two layers of government. We apply vector autoregressions with predetermined variables to unique opinion poll data for the German state of Berlin and the federal level in Germany. State voting intentions for the state and for the federal parliament are the endogenous variables; the federal election trend is treated as predetermined. Our results suggest that shocks in federal parliament voting intention impact state parliament voting intention, but - as a new finding - to the same extent also vice versa. Externalities account for around $10 \%$ to $30 \%$ of variation at the other level of government. The effects differ across parties. Electoral externalities are less pronounced for the conservative party, but increase in times of government. The opposite holds true for left-wing parties.
\end{abstract}

JEL-Codes: D720, H770, C320.

Keywords: elections, opinion polls, time series, party vote shares, federalism.

Xenia Frei

Ifo Institute - Leibniz Institute for Economic Research / Dresden Branch

Dresden / Germany

frei@ifo.de

Robert Lehmann*

Ifo Institute - Leibniz Institute for

Economic Research

at the University of Munich

Germany - 81679 Munich
Sebastian Langer

Leibniz Institute for Ecological Urban and

Regional Development (IOER)

Dresden / Germany

s.langer@ioer.de

Felix Roesel

Ifo Institute - Leibniz Institute for

Economic Research / Dresden Branch

Dresden / Germany

roesel@ifo.de

*corresponding author

This version: February 20, 2017

We thank Lutz Kilian and Niklas Potrafke for their helpful comments and suggestions. We are also grateful to Lisa Giani Contini for her language editing. 


\section{Introduction}

In federal systems, political power is shared among multiple layers of government. Voters, however, often do not discriminate between the performance of a certain party at the sub-national and the federal level. In systems of an opaque 'cooperative federalism' (Hills, 1998), voters cannot observe the origin of bad or good politics. Instead, voters assess 'federal-sub-national' party performance as a whole. The bad performance of, for instance, a federal party leader may then impose a negative externality on the re-election probability of her party incumbents at lower levels of government Rodden, 2006). Empirical studies give strong support to this hypothesis. Federal party performance is found to affect state elections (Gélineau and Bélanger, 2005, Rodden and Wibbels, 2011; Amat et al., 2013, Léon, 2014), and sub-national performance impacts local elections (Curto-Grau et al., 2011). Evidence for externalities that work in the opposite direction is scarce. The results of Spoon and West (2015) and Dinas and Foos (2017) indicate that sub-national politics do have some long-term incumbent effects on federal elections. The simultaneous interactions of multiple layers of government, however, have not been examined yet.

As a further drawback, previous studies on electoral externalities exclusively rely on realized electoral outcomes 11 Given the most common four year legislative intervals, this leads to a very low frequency and time variation in the data. Following the seminal work of Goodhart and Bhansali (1970), political scientists started to tackle this shortcoming by applying time series models to high frequent poll data. This strand of literature focuses on media impulses on election polls (O'Connor et al., 2010), longlasting shocks (Box-Steffensmeier and Smith, 1996; Byers et al., 1997; Dolado et al. 2003), campaigning (Box-Steffensmeier et al., 2009), or macroeconomic determinants of voting intentions (Jones et al., 2014). No study to date analyzes the interactions between high frequency polling data for different layers of government.

This paper fills that gap by investigating the German case. It forms a bridge between the body of literature addressing electoral externalities and research on time series modeling of high frequent poll data. The study that is closest related to our paper is Davidson et al. (2006). The authors find that voters' perception of UK prime minister's performance and the performance of his cabinet are co-integrated. Our approach, however, is different. We model how voting intentions at one level of government respond to a shock at the same or another level of government simultaneously. We employ a vector autoregressive model with predetermined variables using unique opinion poll data for the German state of Berlin (polls for the state and the federal

\footnotetext{
${ }^{1}$ For example, Thorlakson $(2016)$ uses election outcomes in Germany.
} 
election) and for the federal election in Germany. State voting intentions on state elections and on federal elections are treated as endogenous variables, the federal level poll series serves as a predetermined variable that captures the underlying political trend. Our results indicate substantial cross-wise externalities: voting intentions for the state parliament influence federal election polls, and vice versa. The effects vary across parties. For the conservative Christian Democratic Union of Germany (CDU), cross-wise effects are rather weak. In the case of the three more left-wing parties, externalities are stronger and more persistent. This may be partly due to the formation of the German federal government during our sample period. Whereas the CDU was part of the federal government throughout the entire period under investigation, the three more left-wing parties formed the opposition, with the exception of the Social Democratic Party of Germany (SPD), which was in office as a minor partner between 09/2005 and 08/2009 and since 09/2013. We form party-specific sub-samples for periods when a party was part of the federal or state government, and for periods in opposition. In the case of the CDU, externalities were stronger when the CDU was part of the Berlin government. The opposite holds true for the SPD and the German left-wing party (the Left), for which the effects become larger when they are in opposition. Our findings go beyond previous conclusions, which show that mainly federal elections drive the electoral outcomes of state party branches. We control for the underlying general election trend, captured by federal level polls, as a co-founding factor of state level polls. Previous studies did not control for this trend and may thus overestimate the impact of federal level party performance on their sub-national counterparts. We conclude that the performance of state party branches for federal elections is more important than researchers and politicians have acknowledged to date.

The remainder of the paper is organized as follows: Section 2 briefly describes the political background of Germany and the state of Berlin. The data and estimation strategy are introduced in Section 3. In Section 4, we discuss the results and check their robustness to several specifications. We end by offering some conclusions in Section 5 .

\section{Political Background}

We investigate interactions between the federal level and the state level (state of Berlin) in Germany. The federal level decides on pensions, social and healthcare, and defense. The 16 German states are mainly responsible for education (schools and universities), administration and police. Both layers of government are closely interrelated. In terms of fiscal policy, they share common tax sources (value added tax, income tax), 
states receive transfers from the federal level, and they are subject to debt rules set out in the federal constitution apply to both the federal and the state level. The governments of the 16 federal states can veto parts of federal legislation in the upper house of parliament. Rich interconnections also apply to parties. For example, even in federal elections, state party branches decide on party lists. Many leaders of state party branches play a major role in federal politics. Thus, there are rich interactions between both layers of government in Germany (Thorlakson, 2016).

Interactions may result in electoral externalities for several reasons. First, the opaque German system of responsibilities does not allow voters to clearly discriminate among federal level and state level politics (see Anderson, 2006). For example, campaigns in state elections address federal level issues, but also vice versa. Second, politicians often hold offices at the federal, but also at the state level. Therefore, voters can use state elections to vote federal politicians out of office. Third, media coverage of federal politics is more pronounced than of state level politics. Voters may thus use their information on federal politics to form party preferences in state elections. Fourth, voters use state elections to express their opinion on federal politics, and use state elections to impose checks-and-balances on the upper house of parliament. Majorities in the lower and the upper house of parliament often differ substantially. To summarize, election externalities may arguably work in both directions in Germany: from the federal to the state level, and vice versa.

We use a period of vital party competition in Germany at the federal level, but also at the level of the German state of Berlin. Between 2006 and 2016, the conservative CDU dominated the federal government. Table 1 shows that the CDU was present in the federal government for the entire period.

Table 1: Presence in federal or state government

\begin{tabular}{l|c|c|c|c}
\hline Party & $02 / 2006-10 / 2009$ & $11 / 2009-11 / 2011$ & $12 / 2011-12 / 2013$ & $01 / 2014-04 / 2016$ \\
\hline CDU & F & F & F,s & F,s \\
SPD & F,s & s & s & F,s \\
The Greens & - & - & - & - \\
The Left & s & s & - & - \\
\hline
\end{tabular}

Note: The table indicates whether a party was part of the federal (F) or state (s) government. Cells with '-' mark the periods in which the specific party was in the opposition at the federal as well as the state level.

Between 2006 and 2009, and between 2013 and 2016, the CDU formed a Grand coalition with the SPD. The liberal Free Democratic Party (FDP) was the junior partner between 2009 and 2013, but was voted out of the federal parliament in 2013. The Greens and the Left were not part of the federal government between 2006 and 2016. In the German city state of Berlin, by contrast, the dominating party is the 
SPD. Between 2006 and 2011, the SPD formed a left-wing coalition with the Left. After 2011, the conservative CDU joined a Grand coalition led by the SPD. The Green party was not part of the Berlin state government at all. Later on in Section 4, we exploit the differences among the four parties to test whether presence or absence in state and federal governments may drive electoral externalities.

\section{Empirical Strategy}

\subsection{Data}

We rely on three series of monthly opinion polls for the four parties that were present in the state parliament of Berlin and the German federal parliament between 2006 and 2016. Berlin is, by constitution, not only the capital of Germany, but also a federal state. The parties considered are the conservative Christian Democratic Union of Germany (CDU), the Social Democratic Party of Germany (SPD), the Alliance '90/The Greens (The Greens) and the Left-wing party (The Left). On average, these four parties account for around $85 \%$ of voting shares in Berlin. Berlin is the sole German state with monthly polls on voting intentions for the state parliament $\left(\mathrm{Poll}_{s}\right)$ and the federal parliament $\left(\mathrm{Poll}_{f}\right) \mathrm{H}^{2}$ At the federal level, we rely on weekly poll data for the election of the German federal parliament $\left(\mathrm{Poll}_{F}\right)$. Figure 1 is a schematic representation of our poll series.

Figure 1: Schematic representation of the poll series

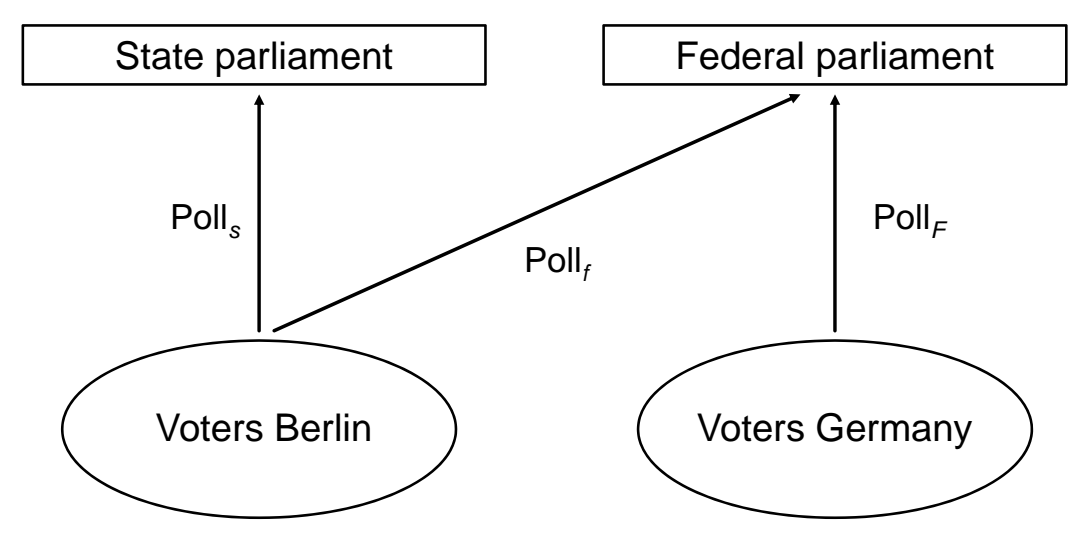

All series start in February 2006 and end in April 2016, which corresponds to a period of about 10 years. Before we can use the data for an empirical analysis, some

\footnotetext{
${ }^{2}$ The Forsa Institute publishes the majority of our data. Few observations stem from Infratest dimap,
} Forschungsgruppe Wahlen and Emnid. All data are obtained from the website www.wahlrecht.de. 
transformations are necessary. The main reason is the difference in the timing of the polls. The poll for the federal election in Germany $\left(\mathrm{Poll}_{F}\right)$ is conducted on a weekly basis (in German it is called Sonntagsfrage), but the voters of Berlin are interviewed on a monthly basis. To construct comparable data, we compute monthly means, in which a month runs from the 15th of the current month to the 14th of the following month $3^{3}$ We end up with three series of 98 observations for each of the four parties.

Figure 2 offers an illustration of our data set. All series vary substantially over time. With the exception of the conservative CDU, polls for the state election (solid black line) fairly reflect the intention to vote for this party at the federal level (solid gray line). There are, however, phases observable for which both voting intentions drift apart from each other. Thus, voters seem to discriminate between different levels of government. The development of the general election trend (dashed line) is also similar to the other two poll series, which grabs a large part of variation in the following empirical model. Further summary statistics are provided in Table 4 in the Appendix.

Figure 2: Opinion polls for the four main parties
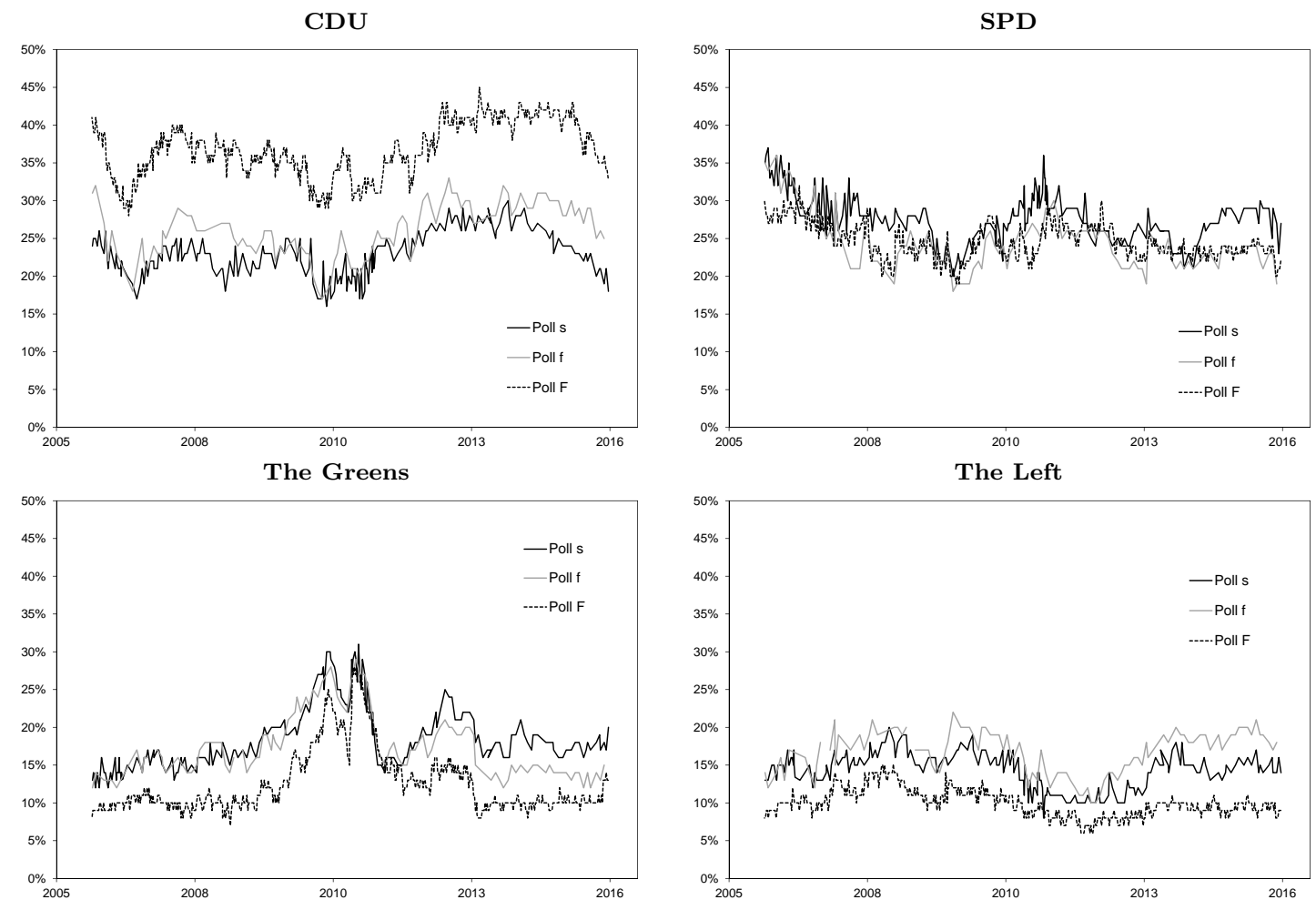

Note: Figures show the state voting intentions for the state parliament ( Poll $_{s}$, solid black line) and the federal parliament $\left(\right.$ Poll $_{f}$, solid gray line), and the polls for the federal parliament ( Poll $_{F}$, dashed line) for the four main parties in Berlin. Series run from February 2006 to April 2016.

\footnotetext{
${ }^{3}$ Few months lack state level data and were excluded. As common in the literature, we treat all observations as equidistant (see, e.g., Nielsen and Shibaev, 2015).
} 


\subsection{Model Specification}

We test the interdependency between our poll data with time series econometric techniques. The most intuitive way of modeling endogenous time series is the standard vector autoregression model with exogenous or predetermined variables $\operatorname{VAR}(p, z)$, discussed, for example, by Lütkepohl (2004) and used with different modifications by Kilian and Park (2009). The model in our notation takes the following form:

$$
\left(\begin{array}{c}
\operatorname{Poll}_{s, t}^{i} \\
\operatorname{Poll}_{f, t}^{i}
\end{array}\right)=\left(\begin{array}{c}
c_{s}^{i} \\
c_{f}^{i}
\end{array}\right)+\mathbf{A}^{i}\left(\begin{array}{c}
\operatorname{Poll}_{s, t-p}^{i} \\
\operatorname{Poll}_{f, t-p}^{i}
\end{array}\right)+\mathbf{B}^{i}\left(\begin{array}{c}
\operatorname{Poll}_{F, t}^{i} \\
\text { Controls }_{t}^{i}
\end{array}\right)+\left(\begin{array}{c}
\varepsilon_{s, t}^{i} \\
\varepsilon_{f, t}^{i}
\end{array}\right)
$$

with the party-specific $(i)$ state level polls for either the state election $\left(\mathrm{Poll}_{s, t}^{i}\right)$ or the federal election $\left(\mathrm{Poll}_{f, t}^{i}\right)$ as the dependent variable. The coefficient estimates for the endogenous variables up to lag $p$ are captured in the $2 \times 2$ matrix $\mathbf{A}^{i}$. All exogenous or predetermined variables such as the federal election trend for party $i\left(\operatorname{Poll}_{F, t}^{i}\right)$ are represented by the second vector, with $\mathbf{B}^{i}$ as the corresponding coefficient matrix. As control variables $\left(\right.$ Controls $_{t}^{i}$ ) we use dummies that account for structural breaks in the poll series and election dates at both the federal and the state level. The poll-specific intercepts are $c_{s}^{i}$ and $c_{f}^{i} ; \varepsilon_{s, t}^{i}$ and $\varepsilon_{f, t}^{i}$ represent the idiosyncratic error term of each equation. Before we set up and estimate the $\operatorname{VAR}(p, z)$ model, we check the time series properties by visual evidence and formal test statistics in the following.

Time Series Specifics and Special Events. From the visual evidence in Figure 2, each party-specific VAR model needs an intercept since polls do not fluctuate around zero. We find no evidence for trending variables or seasonal patterns. However, for the Greens we obviously have to include dummy variables for the monthly polls between March 2010 and October 2011. Two explanations are possible for these structural breaks. First, in 2010, the Greens supported the protest movement against the largescale railway project Stuttgart 21, which reached its peak that year. The second reason for a structural break is the terrible Fukushima Daiichi nuclear disaster in early 2011. Since a German nuclear phase-out is one of the major goals of the Greens, the disaster is perfectly mirrored in the poll results. In the course of these events, the first Green prime minister was elected in a German state (Baden-Wuerttemberg). It is likely that this election generated externalities to other German states, or to the federal level.

We also include two dummies that capture the election dates at the Berlin state and federal level. These dummies are treated as exogenous $4^{4}$ By including these election dummies, we capture increases in media coverage that emerge around elections.

\footnotetext{
${ }^{4}$ All elections are held on a regular basis. The month of the election and the two months before and after the election are coded by a value of one. To all other months we assign a value of zero.
} 
Table 2: Results of the stationarity tests

\begin{tabular}{|c|c|c|c|}
\hline & $\mathrm{ADF}$ & $\mathrm{PP}$ & KPSS \\
\hline \multicolumn{4}{|l|}{ CDU } \\
\hline Poll $_{F}$ & 0.1749 & 0.1476 & 0.0250 \\
\hline $\mathrm{Poll}_{s}$ & 0.5193 & 0.1101 & 0.0700 \\
\hline $\operatorname{Poll}_{f}$ & 0.0203 & 0.0313 & 0.0300 \\
\hline \multicolumn{4}{|l|}{ SPD } \\
\hline Poll $_{F}$ & 0.0101 & 0.0136 & 0.0900 \\
\hline $\mathrm{Poll}_{s}$ & 0.0142 & 0.0213 & 0.1800 \\
\hline Poll $_{f}$ & 0.0053 & 0.0118 & 0.0400 \\
\hline \multicolumn{4}{|c|}{ The Greens } \\
\hline Poll $_{F}$ & 0.3775 & 0.3234 & 0.2000 \\
\hline $\mathrm{Poll}_{s}$ & 0.1267 & 0.1499 & 0.3000 \\
\hline $\mathrm{Poll}_{f}$ & 0.1927 & 0.1903 & 0.1800 \\
\hline \multicolumn{4}{|c|}{ The Left } \\
\hline Poll $_{F}$ & 0.6235 & 0.1893 & 0.0250 \\
\hline $\mathrm{Poll}_{s}$ & 0.2266 & 0.1019 & 0.2500 \\
\hline $\mathrm{Poll}_{f}$ & 0.0945 & 0.0550 & 0.3000 \\
\hline \multicolumn{4}{|c|}{$\begin{array}{l}\text { Note: The table presents p-values for the } \\
\text { tests based on the whole sample from } \\
\text { February } 2006 \text { to April } 2016 \text {. All tests in- } \\
\text { clude an intercept. The ADF and PP test } \\
\text { have a unit root under the null hypothesis. } \\
\text { The KPSS tests against stationarity. }\end{array}$} \\
\hline
\end{tabular}

Stationarity. The next step is to check the stationarity of the series. We apply the augmented Dickey-Fuller test, the Phillips-Perron test, and the KPSS-test. Whereas the first two tests have a unit root under the null, the KPSS-test tests for stationarity. The results are mixed for the four parties, as the p-values in Table 2 indicate. For the SPD and the Left, the tests state that the series are stationary: the null hypotheses can be rejected in the ADF and PP cases, whereas they cannot be rejected in the KPSS test. The results for the CDU and the Greens are not as clear-cut. However, when we perform the tests for the Greens again by excluding the period in 2010/2011 that captures the structural break, the poll series can be treated as stationary. Thus, we treat the entire series as stationary and control for this break via dummy variables, as described above. For the CDU, the series $\mathrm{Poll}_{f}$ is stationary. The tests for the other two series produce p-values that almost reach conventional levels of rejection. As stated by Lütkepohl (2009), the asymptotic properties for the test statistics on the coefficients remain valid, even if each single series is integrated of order one. We therefore also model polls for the CDU in levels. 
Predeterminedness. We treat the federal election trends $\left(\mathrm{Poll}_{F}\right)$ as predetermined in our model. Thus, the federal election polls are assumed to be uncorrelated with future values of the error term. A 'shock' in state-specific polls should not influence future federal election trends because Berlin is too small to leverage federal voting.5 We provide a formal statement by applying Granger Causality tests with a lag length of six months. The detailed results are displayed in Table 3. Under the null hypothesis, the test states that variable $\mathrm{Y}$ does not Granger cause variable $\mathrm{Z}$. Thus, if the null is rejected, then variable $\mathrm{Y}$ can be used to describe or forecast variable $\mathrm{Z}$. The test can also be applied vice versa. Four possible scenarios can emerge: (i) solely variable Y Granger causes variable $\mathrm{Z}(Y \rightarrow Z)$; (ii) solely variable $\mathrm{Z}$ Granger causes variable $\mathrm{Y}(Z \rightarrow Y)$; (iii) both variables impact each other (feedback effects: $Y \rightleftarrows Z$ ) and (iv) there is no relationship $(Y \nrightarrow Z \wedge Z \nrightarrow Y$ ). Table 3 shows the p-values of Granger Causality tests between the federal election and the Berlin polls for state elections $\left(\mathrm{Poll}_{F} \rightarrow\right.$ $\left.\mathrm{Poll}_{s}\right)$, and for federal elections $\left(\mathrm{Poll}_{F} \rightarrow \mathrm{Poll}_{f}\right)$. For the federal parliament election polls, we find that the federal election trend Granger causes the polls for all parties $\left(\mathrm{Poll}_{F} \rightarrow \mathrm{Poll}_{f}\right)$, because all p-values are smaller than 0.1 . In the opposite direction, we find no influence $\left(\right.$ Poll $_{f} \nrightarrow$ Poll $\left._{F}\right)$. These results partially hold for the state election polls. In the case of the Left, we find that the federal election trend Granger causes the state parliament election polls. In the case of the SPD, the two series do not seem to be interconnected. The SPD is a special case because it formed the government in Berlin over the whole observation period. We take this special case into account later when we interpret our results and carry out robustness checks. For the CDU and the Greens, we observe feedback effects. In the case of the CDU the effect is weakly significant. Like the SPD, the Greens are a special case, since the observation period captures the nuclear disaster of Fukushima Daiichi. We consider this special case in our empirical analysis and therefore interpret the result from the Granger Causality tests as an additional hint to treat federal election trends as predetermined variables.

Lag Selection. The party-specific VAR models are estimated and selected iteratively. First, we estimate the model with the smallest number of lags, which is indicated by different lag length selection criteria. We subsequently check in the second step whether the resulting residuals fulfill the requirements of (i) no autocorrelation, (ii) normality

\footnotetext{
${ }^{5}$ Our treatment of predeterminedness falls into line with the argumentation by Lee and $\mathrm{Ni}(2002)$ and Kilian (2009) for the oil price and US GDP growth for some extent. To put their argumentation in a nutshell: they claim that oil price increases are induced by international conditions rather than by the US economy. Thus, the US economy might be too small to influence oil price changes. We transfer the core of this argumentation to our case. For the whole pool of voters surveyed in Germany, the impact of Berlin's voters might be negligible to influence the present or future general election trend.
} 
Table 3: Results of the Granger Causality tests

\begin{tabular}{lcccc}
\hline & CDU & SPD & The Greens & The Left \\
\hline Poll $_{F} \rightarrow$ Poll $_{s}$ & 0.0057 & 0.2139 & 0.0546 & 0.0609 \\
Poll $_{s} \rightarrow$ Poll $_{F}$ & 0.0849 & 0.2069 & 0.0063 & 0.9313 \\
\hline Poll $_{F} \rightarrow$ Poll $_{f}$ & 0.0417 & 0.0011 & 0.0109 & 0.0900 \\
Poll $_{f} \rightarrow$ Poll $_{F}$ & 0.4263 & 0.3314 & 0.1625 & 0.7240 \\
\hline Note: The table presents p-values for the Granger Causality tests \\
based on the whole sample from February 2006 to April 2016. The \\
tests are based on a lag length of six months.
\end{tabular}

and (iii) homoscedasticity. If the residuals fulfill the requirements, there is no need to adjust the model. If these are not fulfilled, we take the second highest lag order and re-estimate the model. The steps are repeated as long as the residuals fulfill the requirements. In the end, we model the parties with the following lags in each specification: CDU with 3 lags; SPD, the Greens and the Left with 1 lag each.

\subsection{Visualization of Election Externalities}

We use two standard time series instruments to visualize election externalities: (1) the impulse response analysis, and (2) the variance decomposition of forecast errors. By controlling for federal election trends, the impulse response identifies whether state election polls affect federal voting intentions at the state level, and vice versa. The crucial step is the identification of the impulse responses. In our case, we cannot derive any ordering from political theory. Thus, the standard Cholesky Decomposition, that imposes a very specific structure on how the shocks propagate through the system, is not applicable. We cannot state whether the contemporaneous correlation between the innovations can be attributed to either the voting intentions for the state parliament or the federal parliament because the polls are collected at the same time among the same pool of voters. In that case, a timing argument for the ordering cannot be justified either. We therefore rely on the alternative way to calculate the impulse responses, proposed by Pesaran and Shin (1998). Their approach generalizes the Cholesky Decomposition and is independent from the ordering of the variables. Thus, we can check whether voting intentions for the state parliament $\left(\mathrm{Poll}_{s}\right)$ and for the federal parliament $\left(\mathrm{Poll}_{f}\right)$ influence each other without imposing restrictions on the system by simultaneously controlling for the federal election trends $\left(\mathrm{Poll}_{F}\right)$. We present the impulse responses for a period of 24 months. If voters are myopic, then no effect for longer time horizons should be visible, and the responses will die out rapidly. We show bands based on two standard errors, generated from a Monte Carlo simulation with 1,000 repetitions. 
In a second step, we conduct a forecast error variance decomposition in order to highlight the interdependence of the endogenous variables. The idea of a variance decomposition is straightforward: we illustrate how much of the forecast error of a specific endogenous variable can be explained by exogenous shocks of another variable in the system. We thus address how much percent of the forecast error of, for instance, the voting intention for the federal parliament $\left(\mathrm{Poll}_{f}\right)$ can be attributed to a shock in voting intentions for the state parliament $\left(\mathrm{Poll}_{s}\right)$, and vice versa. For the variance decomposition we have to apply the Cholesky factorization. To check the validity of the variance decomposition, however, we apply both orderings. We also present the variance decomposition for a period of 24 months. The bands are based on two Monte Carlo standard errors with 1,000 repetitions.

\section{Results}

\subsection{Baseline Estimations}

We show impulse responses and the corresponding variance decomposition based on our VAR estimations. The detailed estimation results are presented in Table 5 in the Appendix. Federal election trends $\left(\mathrm{Poll}_{F}\right)$ are treated as predetermined, polls for the state elections and for federal elections serve as endogenous variables. We pay particular attention to cross-wise reactions between voting intentions for the federal parliament or the state parliament $\left(\mathrm{Poll}_{f} \rightarrow \mathrm{Poll}_{s}\right.$; $\left.\mathrm{Poll}_{s} \rightarrow \mathrm{Poll}_{f}\right)$. Thus, we do not analyze how persistent shocks within specific poll series are ${ }^{6}$ We analyze each of the four parties separately. In Figure 3 we first look at impulse responses that follow a shock in federal election polls and affect state parliament voting intentions $\left(\right.$ Poll $_{f} \rightarrow$ $\mathrm{Poll}_{s}$ ). This channel has been investigated in previous studies. In a second step, we present the responses of federal parliament voting intentions to impulses for the statelevel $\left(\right.$ Poll $_{s} \rightarrow$ Poll $\left._{f}\right)$ in Figure 4, a phenomenon that has not been investigated in the literature on this topic to date 7 And finally, we decompose the forecast error variance that illustrates the proportion to which a shock on voting intention in federal elections impacts the intention to vote in state elections and vice versa (see Figure 5 and 6 ).

Impulse Responses. We start with the impulses of one standard deviation shock in voting intentions for the federal parliament and the corresponding responses for state

\footnotetext{
${ }^{6}$ The results for univariate impulse responses can be found in Figure 8 and Figure 9 in the Appendix.

${ }^{7}$ Taking log-odds as proposed, for example, by Davidson et al. (2006) does not change our results as it can be seen from Figure 10 and Figure 11 in the Appendix. A log-odd $Y_{t}$ can be computed in the following way: $Y_{t}=\log \left(y_{t} /\left(100-y_{t}\right)\right)$.
} 
parliament voting intentions $\left(\mathrm{Poll}_{f} \rightarrow \mathrm{Poll}_{s}\right)$. Figure 3 presents the impulse responses (dark line with dots) for the four parties (CDU - top left panel, SPD - top right panel, the Greens - bottom left panel, and the Left - bottom right) and a horizon of 24 months each. The dashed lines limit the bands of two standard errors for each response. Basically, we find positive election externalities from the federal to the state level for all parties, which corroborate the findings of the existing literature. However, their strength and persistence remarkably differ across parties. A rather small and short-lived effect of 2 months is observable for the CDU. The responses rapidly die out afterwards, because substantial parts of the variation are grabbed by the federal election trend. The CDU was in power at the federal level throughout the entire observation period. However, a positive influence on votes cast for the CDU can be seen at the state level, if the voting intention at the federal level increases. We therefore expect federal politics to have a sizable impact on the Berlin CDU. For the Greens and SPD, we find similar patterns in some respects. We observe positive election externalities from the federal level to state parliament voting intentions for a period of 3 months. Election externalities thus last longer compared to the CDU. The responses for the Left are most persistent. An impulse of one standard deviation in federal voting intentions induces positive and significant responses to vote for the Left at the state level for up to 5 months.

Figure 3: Impulse responses for the direction $\mathrm{Poll}_{f} \rightarrow \mathrm{Poll}_{s}$
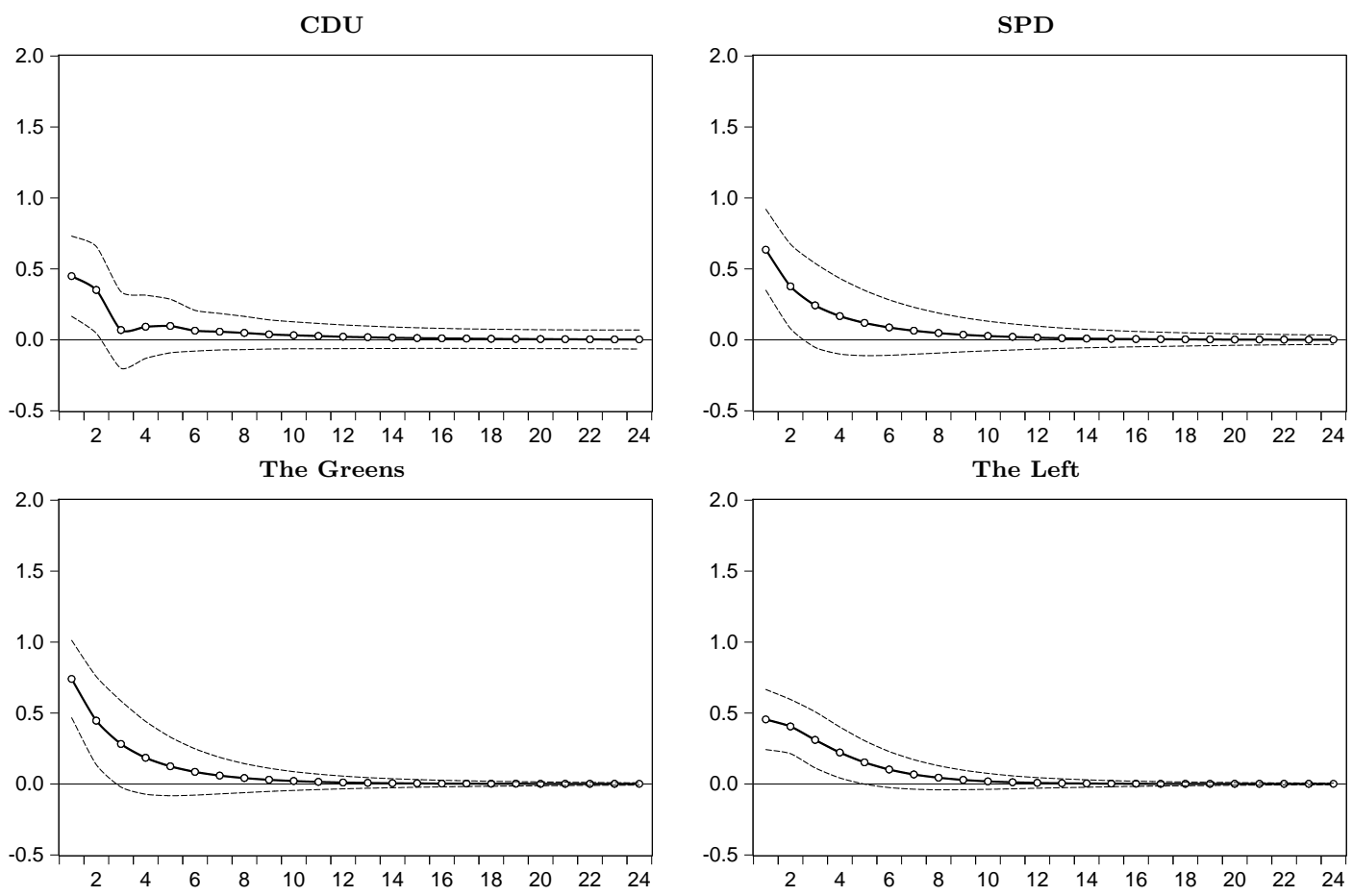

Note: Dotted lines present the impulse response functions up to 24 months. Dashed lines display bands of two standard errors. 
In Figure 4, we present the responses of federal parliament voting intentions, resulting from impulses of polls for the state election $\left(\mathrm{Poll}_{s} \rightarrow \mathrm{Poll}_{f}\right)$. The figure is constructed in the same manner as Figure 3 . Now we find substantial positive election externalities from the state to the federal level. This finding has been neglected by the existing literature on this topic to date. Again, strength and persistence varies across parties. The effects for CDU and the Greens are the least persistent. For the CDU, we stick to the federal elections argumentation again. The CDU was in power over the whole period; thus, a large part of the variation is grabbed by the federal election trend. We do, however, find a positive spillover for the first month, which is as large as the reverse reaction. For the Greens, we observe a positive and significant impact up to 2 months. Election externalities from state to federal parliament voting intentions are somewhat shorter compared to the reverse effect. We hypothesize that one reason for this observation might be that the Green state party branch differs substantially from its federal counterpart in terms of ideology. Shocks in the voting intuition for the more conservative federal party branch of the Greens may thus affect voting intentions for the more open-minded Berlin branch, but not vice versa. Turning to the SPD, the positive effects of state level voting intentions last longer ( 5 months) compared to the reverse responses from federal to state election polls. Thus, the state level impact is much clearer in the case of the Social Democrats. One explanation might be that the SPD has been the leading party in Berlin for the whole observation period, which dominates the ambiguous role at the federal level of the SPD (legislative period 2009 to 2013: opposition; for all other years in the sample: junior partner in a Grand coalition). With a length of 2 months, we find a short-lived effect for the Left. The persistence is only half as high as the reverse impact at 5 months $\left(\right.$ Poll $_{f} \rightarrow$ Poll $_{s}$ in Figure 3). The difference in reaction functions might be induced by the changing role of the Left for the state of Berlin. From 2002 to 2011, the SPD formed a coalition with the Left in the Berlin parliament and enacted deep budgetary cuts. Voters of the Left, which prefer a larger public sector (see Potrafke, 2017) and are likely to express their protest attitudes, might have penalized the political actions of the Left as part of the state parliament, but support the clear cut left-wing policy of the federal party branch.

To sum up so far: we find significant cross-wise election externalities for the four parties under consideration. The length and persistence of the effects, however, vary substantially across parties. In the next step, we turn to the variance decomposition of forecast errors. 
Figure 4: Impulse responses for the direction $\mathrm{Poll}_{s} \rightarrow \mathrm{Poll}_{f}$
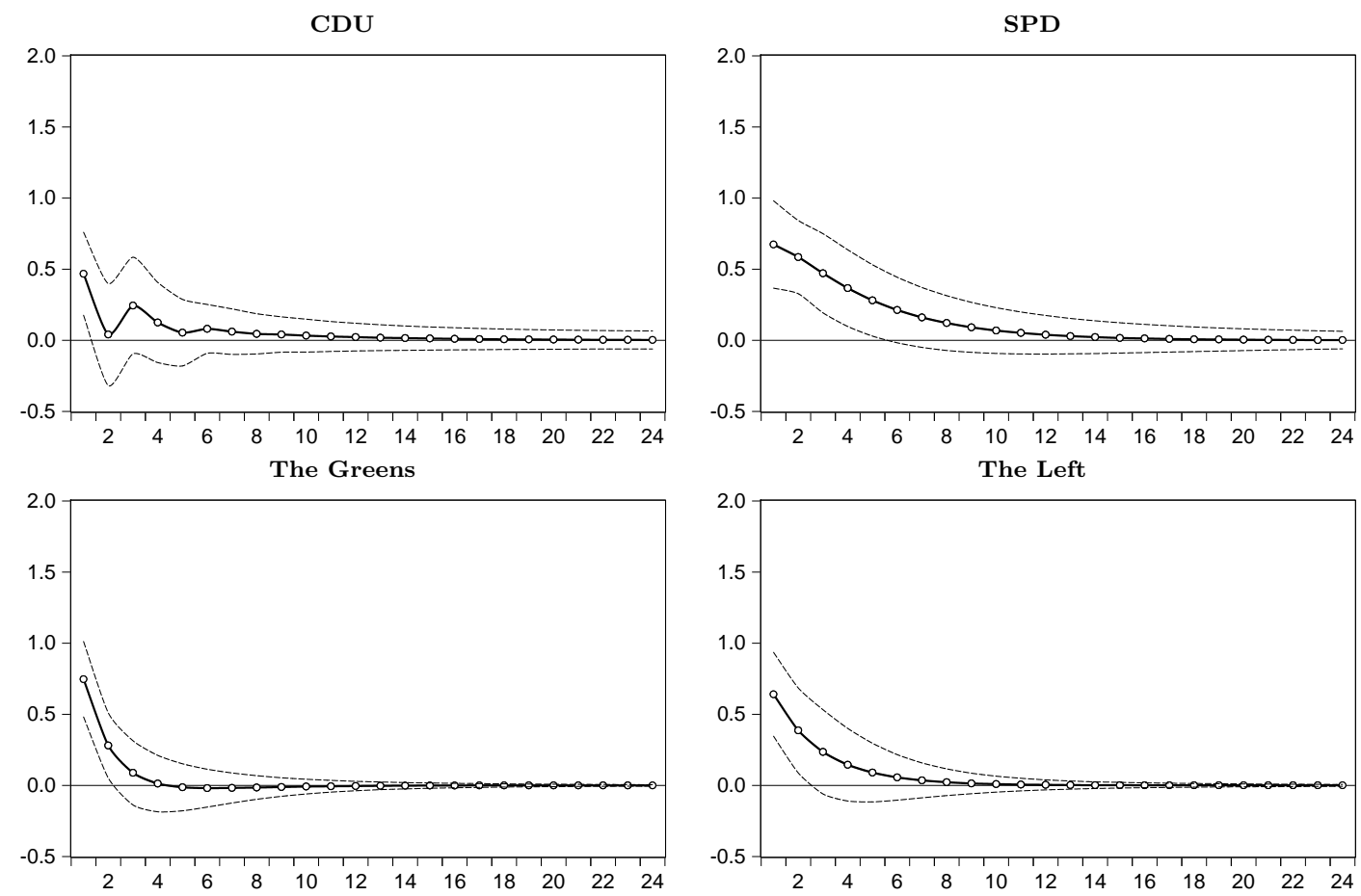

Note: Dotted lines present the impulse response functions up to 24 months. Dashed lines display bands of two standard errors.

Variance Decomposition. A variance decomposition of forecast errors illustrates the proportion to which shocks in federal parliament voting intentions persist in polls for state elections, and vice versa. Again, we start with the decomposition of state level voting intentions in Figure 5. The proportion of voting intentions for the state parliament that stems from shocks in polls for the federal election is shown in dark gray bars. The remaining part of the variance (shares add up to 100\%) is attributed to the inherent dynamics of the original series. We arrange the four parties as before and present the decomposition for a horizon of 24 months each. The variance of the state parliament voting intentions for the CDU can only be fractionally explained by federal election polls. It reaches its peak of $14 \%$ at the second month after the shock and stabilizes at almost $11 \%$ afterwards. Therefore, $11 \%$ of the variance of state parliament voting intentions $\left(\mathrm{Poll}_{s}\right)$ can be attributed to the variance of $\mathrm{Poll}_{f}$ in the long term. The development of explained variance for the SPD is fairly small. At over $18 \%$, the strongest effect is observable 1 month after the shock and converges to $13 \%$ afterwards. A very large share in the variance of state level voting intentions can be explained by the attitude towards federal elections in the case of the Greens. The largest effect of almost $30 \%$ shows up 1 month after the shock and subsequently stabilizes at $25 \%$. Turning to the Left, we find a sharp increase in the variance decomposition with a 
Figure 5: Variance decomposition for state level voting intentions $\mathrm{Poll}_{s}$
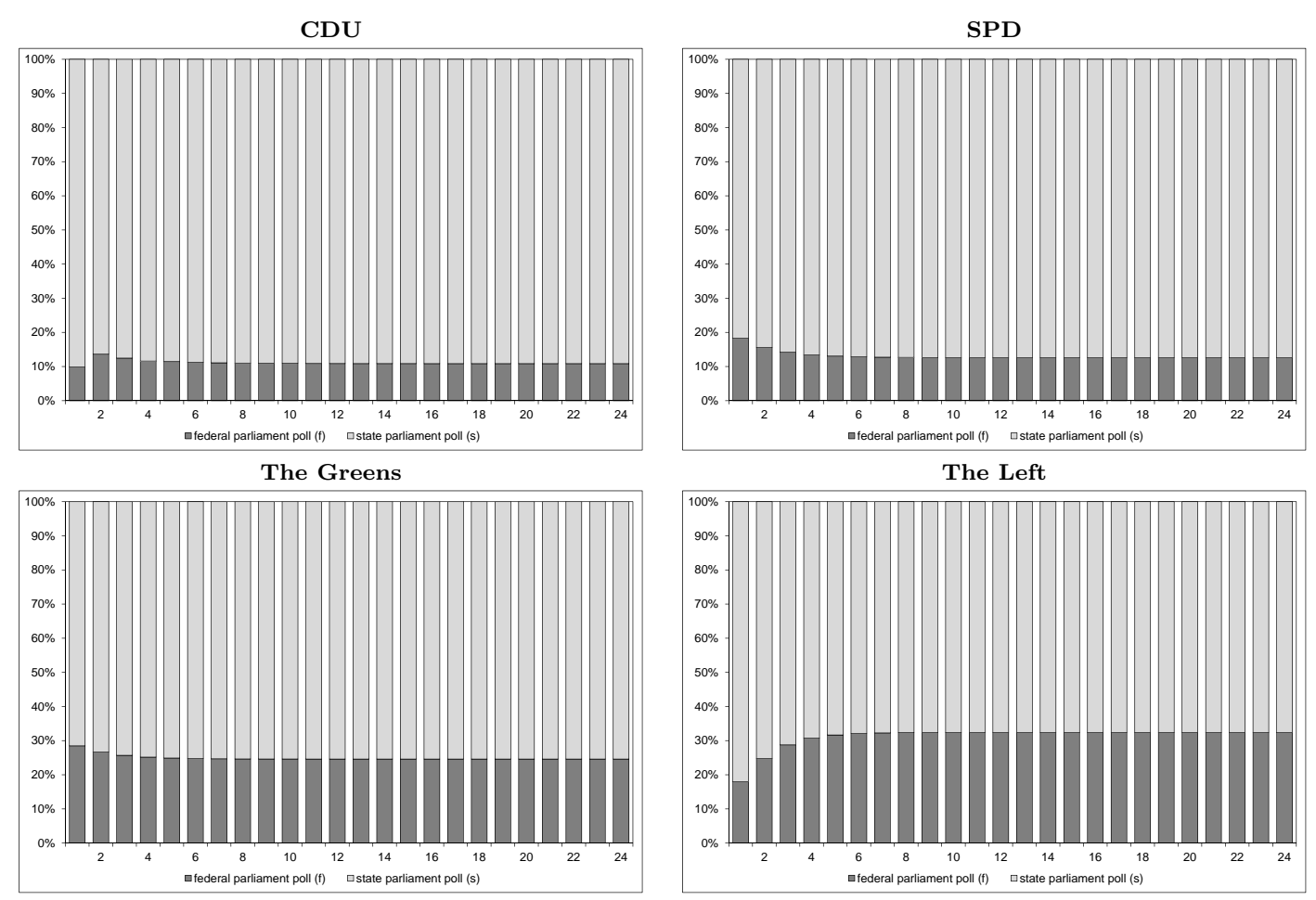

larger horizon. Starting with $18 \%$ of explained variance, the proportion rises to $32 \%$ in the sixth month. Thus, almost one third of the forecast error variance of the state election polls for the Left can be explained by the federal voting intention for the Left. In the end, we can conclude at this stage that the decomposition of election polls for the state parliament confirms our findings of substantial externalities from the federal to the state level.

Finally, we present the variance decomposition for federal level voting intentions $\left(\right.$ Poll $\left._{f}\right)$. Figure 6 shows the corresponding diagrams. In this figure, the proportions of forecast error variance of federal level voting intentions that result from polls on state elections are displayed in dark gray. As in the case of state level voting intentions, the proportion for the CDU is rather small compared to that of other parties. The proportion rises only slightly until the eighth month and stabilizes at $12 \%$ afterwards. In contrast to Figure 5, a large decomposition effect can be found for SPD and thus a concise similarity to the development of the proportion of the Left in Figure 5 (bottom right panel). For the first month, the proportion amounts to over $18 \%$ and rises to almost $37 \%$ in the tenth month after the shock. Afterwards it persists at this level. The share of explained variance for the Greens is very stable over time at almost $30 \%$. Thus, the patterns are nearly the same as for the reversed cross-wise reaction. For the Left we find a similar movement as for the CDU. On average, the proportion of 
Figure 6: Variance decomposition for federal level voting intentions Poll $_{f}$
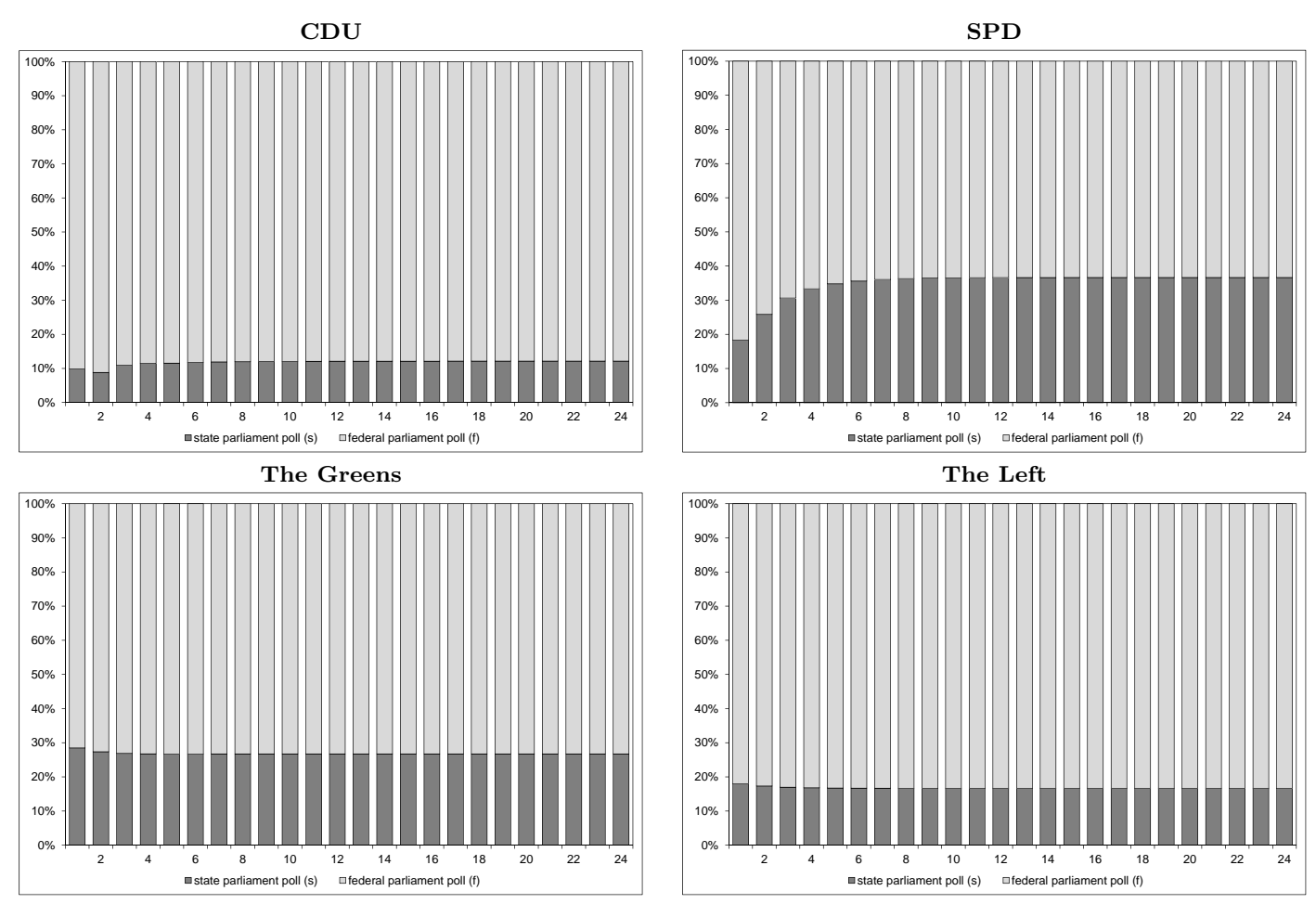

explained variance is $17 \%$. All in all, the variance decomposition of federal voting intentions also mirrors the results from the former impulse response analysis: state level voting intentions influence federal election polls.

To put the results in a nutshell: we find substantial election externalities in both directions and for all of the four parties. For the largest German party, the CDU, we find only weak cross-wise influence of voting intentions. Most of the variation is grabbed by the federal election trend, since the CDU was in power throughout the whole observation period. For the SPD, the larger externalities in terms of strength and persistence are found for state level voting intentions on federal election polls. Thus, the federal-acting SPD gains positive externalities (or loses in the negative case) from the strong Berlin state branch. For the Alliance '90/The Greens and the German left-wing party, the opposite is true. For these two parties we find larger externalities for the state-specific polls. There are, however, also reverse effects.

Figure 5 and Figure 6 illustrate almost symmetric externalities for the CDU and the Greens. Whereas the CDU was in power at the federal level throughout our entire observation period, the Greens always formed the opposition in the federal parliament (and in the state parliament as well). For the SPD and the Left, we find asymmetric effects. Whereas election externalities from the state to the federal level are stronger in the SPD case, the opposite is true for the Left. One major explanation might be 
the presence in the state or the federal government. We check whether our results are robust in that respect in the following section.

\subsection{Robustness Checks}

All in all, we run three robustness checks. First, we exclude the dummies for federal and state elections. With this check we can ensure that our results are not driven by these dummies that cover increases in media coverage around elections, but rather show that election externalities are a permanent phenomenon. The exclusion of the election dummies does not change our baseline results (see the impulse responses in Figure 12 and Figure 13 in the Appendix). It is therefore reasonable to think that election externalities are also present and persistent independent of elections taking place, since the polls are published on a regular basis in a local newspaper, the Berliner Zeitung. Coverage does not change when it comes to elections.

In our second robustness check, we divide the sample in two different ways to verify that certain periods do not trigger the results. First, we simply half the sample in 2011. In a second step, we examine different time periods in which parties were either part of the federal or state government or in opposition. By dividing the sample in the middle, the estimation for the CDU produces very large and imprecisely estimated bands for the impulse responses. However, the strength and patterns of the impulse responses remain untouched compared to the estimation of the whole sample. For the $\mathrm{SPD}$, we find very robust results with larger effects for the first half of the sample. The results for the Greens do not change at all. For the Left, we also find very robust results, with larger effects for the second half of the sample.

The second splits of the samples are based on the periods for which each party was either in the federal or state government, or was part of the opposition. Table 1 in Section 2 gave an overview of these periods for each party. With the exception of the Greens, which were always part of the opposition, we can distinguish between two subperiods for each party. The CDU was in power at the federal level throughout the whole observation period. In December 2011, however, the CDU formed a Grand coalition with the SPD in Berlin. Thus, we split the sample for the CDU at November 2011. By contrast, the SPD has always led the state government. However, the SPD was not part of the federal government between November 2009 and December 2013. Thus, we can use these two sub-periods for the SPD. As indicated previously, the Greens did not form a government at the federal or at the state level. The Left was part of the Berlin government until November 2011 and subsequently formed the opposition.

In order to densify the findings from this second sample split, we introduce Figure 7. For each of the four parties, this figure shows the responses of $\mathrm{Poll}_{f}$ and $\mathrm{Poll}_{s}$ up to six 
months, followed by an impulse of $\mathrm{Poll}_{s}$ or $\mathrm{Poll}_{f}$. The $x$-axis represents the responses that result from the baseline estimation. These responses can also be seen in Figure 3 and Figure 4. The $y$-axis shows the responses from the sub-sample estimates. Each $x$ - $y$ combination represents a pair of responses that stem from different estimations. Circles are combinations of responses between the baseline and the specific sub-sample when a party was part of the government (either federal or state). Periods of opposition are visualized by a triangle. As mentioned before, we cannot distinguish such subperiods for the Greens, because the Greens were never part of the state or federal government. Thus, we estimate the responses for the pre- and post-nuclear period of the Fukushima Daiichi disaster and thereby exclude the structural break that emerges for this party. In order to indicate significant responses, we change the color and size of the respective $x$ - $y$-combination. If a circle/triangle is depicted in black, the response is statistically significant different from zero in the baseline and in the sub-sample estimation. If a circle/triangle is depicted in gray, the response lacks significance in the sub-sample estimation, but not in the baseline estimation. Finally, we add the $45^{\circ}$-line. Circles/triangles on this line suggest similar baseline and sub-sample estimates. If a pair lies under (above) the $45^{\circ}$-line, the response is larger (smaller) in the baseline estimation compared to the specific sub-sample.

The responses for the CDU are larger in the period during which the CDU forms a Grand Coalition with the SPD in Berlin compared to the baseline. The opposite holds true for the period during which the CDU formed the opposition in Berlin. However, these three responses lack statistical significance (gray triangles) because the estimations for the CDU produce very large standard errors in the opposition period. Therefore, the overall effects for the CDU are driven by the period for which the CDU formed the government at the federal, as well as the state level. In the case of the $\mathrm{SPD}$, we find that the responses are larger for the period in which the SPD was part of the opposition at the federal level. The responses are smaller for the period during which the SPD formed a Grand Coalition with the CDU at the federal level because the circles are located below the $45^{\circ}$-line. As in the case of the CDU, some responses lack statistical significance, especially when the SPD was in opposition. As indicated before, the effects for the Left are larger for the second half of the sample that corresponds with their time of being part of the Berlin opposition. At this point, we have to stress the partisan argument again. Voters may have penalized the budgetary cuts of the Left in times when it formed the Berlin government with the SPD. Afterwards, by taking the role of the opposition again, the state-branch of the Left might have moved more towards the clear cut left-wing policy of the federal branch, thus, generating larger election externalities. The results for the Greens are very robust to sub-periods. 
Figure 7: Response comparison between the baseline and the sub-sample estimations

CDU

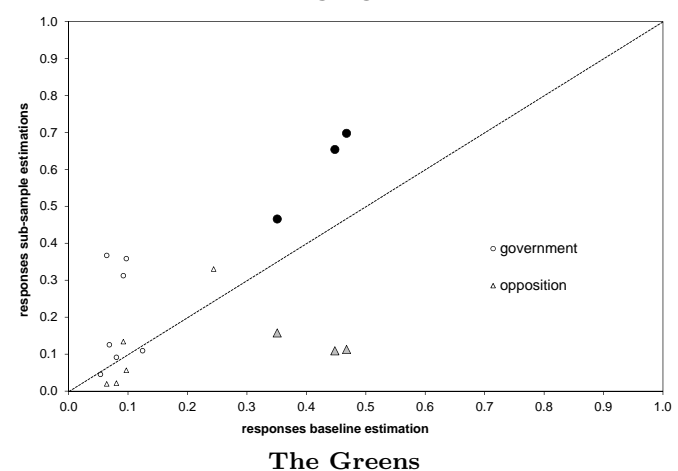

The Greens

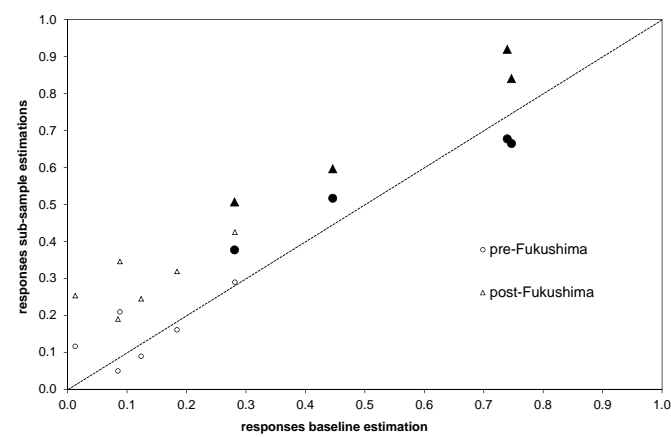

SPD

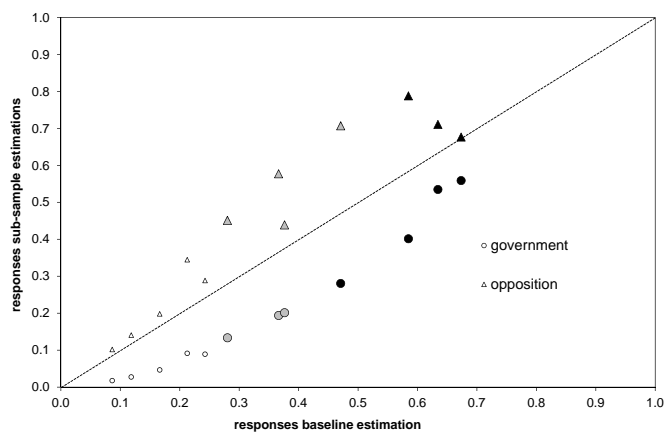

The Left

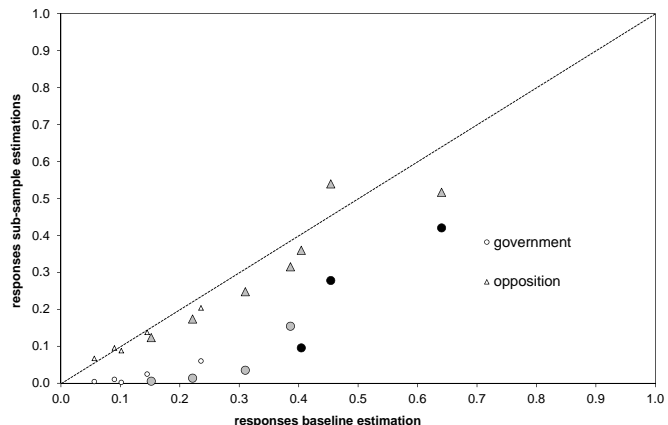

Note: Each pair represents a combination of responses between the baseline and the sub-sample estimations. Circles mark the subsample for which a party formed the government (or the pre-nuclear period of the Fukushima Daiichi disaster in the case of the Greens). On the opposite, triangles display the period where the party was part of the opposition (or the post-nuclear period of the Fukushima Daiichi disaster in the case of the Greens). Larger black circles/triangles present those responses that are significant in the baseline and sub-sample estimations. If a circle/triangle is hold in gray, the response becomes insignificant in the sub-sample, whereas it is significant in the baseline estimation.

However, the responses and therefore the externalities are larger in the post-nuclear period of the Fukushima Daiichi disaster.

In the last robustness check, we sequentially include further control variables that either capture general economic conditions, labor market conditions or, consumer confidence. This robustness check grabs externalities between polls that may be attributed to rather exogenous developments, and not to political party performance at different layers of government. To measure the general economic conditions in Germany, we use the Ifo Business Climate Index as a leading indicator, or monthly growth rates of industrial production. Another source of influence on voting polls is consumer sentiment. Thus we add the Consumer Confidence Indicator provided by the European Commission. Since these three indicators are measured at the German federal level, we also want to grab Berlin-specific developments. We therefore either add the monthly unemployment rate of Berlin, employment growth, or the development in total vacancies. None of these additional control variables changes our baseline results. 8

\footnotetext{
${ }^{8}$ Detailed results from the robustness checks with additional controls are available upon request.
} 


\section{Conclusion}

We find that federal parliament voting intention has a robust and substantial impact on state level election polls. However, we also document large election externalities that work vice versa, and have been neglected by the literature on this topic to date. Externalities from other levels of government account for at least $10 \%$ to $30 \%$ of the variation in voting intentions. We conclude that the performance of state party branches is far more important for federal elections than researchers and politicians have acknowledged to date. Party leaders should be aware of these electoral externalities and may impose a more sufficient corporate identity on state party branches.

The extent of electoral externalities also seems to vary with the party-specific position in the political landscape. In the case of the conservative party in Germany (CDU), we find larger externalities when the CDU was part of state parliament compared to periods in opposition. The opposite is true for the two left-wing parties, the Social Democrats of Germany (SPD) and the Left. For these two parties, we find stronger externalities when they were part of the opposition (at the federal level for the SPD and the state level for the Left). We suggest that further investigation of the role of government participation on electoral externalities is needed. However, our conclusions are drawn from a series of monthly poll data for the German state Berlin and federal elections in Germany. Further research may use more extended series and investigate the interaction of voting intention in federal systems in the very long-run.

\section{References}

Amat, F., Jurado, I. and LÉon, S. (2013). Electoral externalities in decentralized parliamentary democracies. mimeo.

Anderson, C. D. (2006). Economic Voting and Multilevel Governance: A Comparative Individual-Level Analysis. American Journal of Political Science, 50 (2), 449-463.

Box-Steffensmeier, J. M., Darmofal, D. and Farrell, C. A. (2009). The Aggregate Dynamics of Campaigns. Journal of Politics, 71 (1), 309-323.

— and Smith, R. (1996). The Dynamics of Aggregate Partisanship. American Political Science Review, 90 (3), 567-580.

Byers, D., Davidson, D. and Peel, D. (1997). Modelling Political Popularity: An Analysis of Long-Range Dependence in Opinion Poll Series. Journal of the Royal Statistical Society Series A, 160 (3), 471-490. 
Curto-Grau, M., Solé-Ollé, A. and Sorribas-Navarro, P. (2011). The returns to partisan alignment between regional and local governments. mimeo.

Davidson, D., Peel, D. and Byers, D. (2006). Support for Governments and Leaders: Fractional Cointegration Analysis of Poll Evidence from the UK, 19602004. Studies in Nonlinear Dynamics and Econometrics, 10 (1), 1-23.

Dinas, E. and Foos, F. (2017). The national effects of subnational representation: How parties' access to regional parliaments shapes national elections. Quarterly Journal of Political Science, forthcoming.

Dolado, J., Gonzalo, J. and Mayoral, L. (2003). Long-Range Dependence in Spanish Political Opinion Poll Series. Journal of Applied Econometrics, 18 (2), 137 155.

Gélineau, F. and Bélanger, E. (2005). Electoral Accountability in a Federal System: National and Provincial Economic Voting in Canada. Publius, 35 (3), 407-424.

Goodhart, C. and Bhansali, R. (1970). Political Economy. Political Studies, 18 (1), $43-106$.

Hills, R. (1998). The Political Economy of Cooperative Federalism: Why State Autonomy Makes Sense and 'Dual Sovereignty' Doesn't. Michigan Law Review, 96 (4), 813-944.

Jones, M., Nielsen, M. and Popiel, M. (2014). A fractionally cointegrated VAR analysis of economic voting and political support. Canadian Journal of Economics, 47 (4), 1078-1130.

Kilian, L. (2009). Not All Oil Price Shocks Are Alike: Disentangling Demand and Supply Shocks in the Crude Oil Market. American Economic Review, 99 (3), 10531069.

- and PARK, C. (2009). The Impact of Oil Price Shocks on the U.S. Stock Market. International Economic Review, 50 (4), 1267-1287.

LEE, K. and Ni, S. (2002). On the dynamic effects of oil price shocks: a study using industry level data. Journal of Monetary Economics, 49 (4), 823-852.

LÉON, S. (2014). How does decentralization affect electoral competition of state-wide parties? Evidence from Spain. Party Politics, 20 (3), 391-402. 
Lütkepohl, H. (2004). Vector Autoregressive and Vector Error Correction Models. In H. Lütkepohl and M. Krätzig (eds.), Applied Time Series Econometrics, Chapter 3, Cambridge University Press, pp. 86-158.

- (2009). Econometric Analysis with Vector Autoregressive Models. In D. A. Belsley and E. J. Kontoghiorghes (eds.), Handbook of Computational Econometrics, Chapter 8, John Wiley \& Sons, Ltd., pp. 281-319.

Nielsen, M. and Shibaev, S. (2015). Forecasting daily political opinion polls using the fractionally cointegrated VAR model. Queen's Economics Department Working Paper No. 1340.

O’Connor, B., Balasubramanyan, R., Routledge, B. and Smith, N. (2010). From tweets to polls: Linking text sentiment to public opinion time series. Proceedings of the Fourth International AAAI Conference on Weblogs and Social Media.

Pesaran, M. H. and Shin, Y. (1998). Impulse Response Analysis in Linear Multivariate Models. Economics Letters, 58 (1), 17-29.

Potrafke, N. (2017). Partisan Politics: The empirical evidence from OECD panel studies. Journal of Comparative Economics, forthcoming.

Rodden, J. (2006). Hamilton's Paradox: The Promise and Peril of Fiscal Federalism. Cambridge University Press.

- and WibBels, E. (2011). Dual accountability and the nationalization of party competition: Evidence from four federations. Party Politics, 17 (5), 629-653.

Spoon, J.-J. and West, K. J. (2015). Bottoms up: How subnational elections predict parties' decisions to run in presidential elections in Europe and Latin America. Research 85 Politics, 2 (3), 1-8.

Thorlakson, L. (2016). Electoral Linkages in Federal Systems: Barometer Voting and Economic Voting in the German Länder. Swiss Political Science Review, 22 (4), 608-624. 


\section{Appendix}

Table 4: Descriptive statistics

\begin{tabular}{|c|c|c|c|c|c|}
\hline & \multicolumn{5}{|c|}{ Total sample } \\
\hline & Obs. & Mean & Std. Dev. & Min & Max \\
\hline \multicolumn{6}{|l|}{ CDU } \\
\hline Poll $_{F}$ & 98 & 36.70 & 3.58 & 29.50 & 42.40 \\
\hline $\mathrm{Poll}_{s}$ & 98 & 23.19 & 2.84 & 16.00 & 29.00 \\
\hline Poll $_{f}$ & 98 & 26.03 & 3.64 & 17.00 & 33.00 \\
\hline \multicolumn{6}{|l|}{ SPD } \\
\hline Poll $_{F}$ & 98 & 24.53 & 2.09 & 19.75 & 30.00 \\
\hline $\mathrm{Poll}_{s}$ & 98 & 27.30 & 3.00 & 20.00 & 36.50 \\
\hline Poll $_{f}$ & 98 & 24.42 & 3.54 & 18.00 & 36.00 \\
\hline \multicolumn{6}{|c|}{ The Greens } \\
\hline $\operatorname{Poll}_{F}$ & 98 & 12.90 & 4.32 & 8.00 & 27.25 \\
\hline $\mathrm{Poll}_{s}$ & 98 & 18.86 & 3.99 & 13.00 & 30.00 \\
\hline $\mathrm{Poll}_{f}$ & 98 & 17.36 & 4.24 & 12.00 & 29.00 \\
\hline \multicolumn{6}{|c|}{ The Left } \\
\hline Poll $_{F}$ & 98 & 9.78 & 1.70 & 6.20 & 14.20 \\
\hline $\mathrm{Poll}_{s}$ & 98 & 14.10 & 2.30 & 10.00 & 19.00 \\
\hline Poll $_{f}$ & 98 & 16.64 & 2.88 & 10.00 & 22.00 \\
\hline
\end{tabular}

Note: The table shows the summary statistics of our data set. Series are on a monthly basis and cover the period from February 2006 to April 2016. 
Table 5: Results of the baseline estimation

\begin{tabular}{|c|c|c|c|c|c|c|c|c|}
\hline & \multicolumn{2}{|c|}{ CDU } & \multicolumn{2}{|c|}{ SPD } & \multicolumn{2}{|c|}{ The Greens } & \multicolumn{2}{|c|}{ The Left } \\
\hline & $\operatorname{Poll}_{f}$ & $\mathrm{Poll}_{s}$ & $\operatorname{Poll}_{f}$ & $\mathrm{Poll}_{s}$ & $\operatorname{Poll}_{f}$ & $\mathrm{Poll}_{s}$ & $\operatorname{Poll}_{f}$ & $\mathrm{Poll}_{s}$ \\
\hline \multicolumn{9}{|c|}{ Inherent dynamics } \\
\hline$L \operatorname{Poll}_{f}$ & $\begin{array}{l}0.37^{* * *} \\
(0.10)\end{array}$ & $\begin{array}{c}0.13 \\
(0.09)\end{array}$ & $\begin{array}{l}0.35^{* * *} \\
(0.08)\end{array}$ & $\begin{array}{l}-0.08 \\
(0.08)\end{array}$ & $\begin{array}{l}0.46^{* * *} \\
(0.10)\end{array}$ & $\begin{array}{l}-0.05 \\
(0.10)\end{array}$ & $\begin{array}{l}0.66^{* * *} \\
(0.09)\end{array}$ & $\begin{array}{c}0.14^{* *} \\
(0.07)\end{array}$ \\
\hline$L^{2} \operatorname{Poll}_{f}$ & $\begin{array}{l}-0.18^{*} \\
(0.10)\end{array}$ & $\begin{array}{l}-0.16 \\
(0.10)\end{array}$ & - & - & - & - & - & - \\
\hline$L^{3} \operatorname{Poll}_{f}$ & $\begin{array}{c}0.04 \\
(0.09)\end{array}$ & $\begin{array}{c}0.00 \\
(0.09)\end{array}$ & - & - & - & - & - & - \\
\hline$L \mathrm{Poll}_{s}$ & $\begin{array}{l}-0.09 \\
(0.12)\end{array}$ & $\begin{array}{l}0.35^{* * *} \\
(0.12)\end{array}$ & $\begin{array}{l}0.23^{* * *} \\
(0.09)\end{array}$ & $\begin{array}{l}0.80^{* * *} \\
(0.08)\end{array}$ & $\begin{array}{l}-0.04 \\
(0.08)\end{array}$ & $\begin{array}{l}0.70^{* * *} \\
(0.08)\end{array}$ & $\begin{array}{l}-0.03 \\
(0.13)\end{array}$ & $\begin{array}{l}0.44^{* * *} \\
(0.10)\end{array}$ \\
\hline$L^{2} \mathrm{Poll}_{s}$ & $\begin{array}{c}0.26^{* *} \\
(0.12)\end{array}$ & $\begin{array}{c}0.26^{* *} \\
(0.12)\end{array}$ & - & - & - & - & - & - \\
\hline$L^{3} \mathrm{Poll}_{s}$ & $\begin{array}{l}-0.05 \\
(0.12)\end{array}$ & $\begin{array}{c}0.12 \\
(0.12)\end{array}$ & - & - & - & - & - & - \\
\hline \multicolumn{9}{|c|}{ Control variables } \\
\hline $\operatorname{Poll}_{F}$ & $\begin{array}{l}0.72^{* * *} \\
(0.08)\end{array}$ & $\begin{array}{l}0.23^{* * *} \\
(0.08)\end{array}$ & $\begin{array}{l}0.66^{* * *} \\
(0.12)\end{array}$ & $\begin{array}{c}0.12 \\
(0.11)\end{array}$ & $\begin{array}{l}0.47^{* * *} \\
(0.09)\end{array}$ & $\begin{array}{l}0.29^{* * *} \\
(0.08)\end{array}$ & $\begin{array}{l}0.50^{* * *} \\
(0.13)\end{array}$ & $\begin{array}{l}0.50^{* * *} \\
(0.10)\end{array}$ \\
\hline Election $_{F}$ & $\begin{array}{l}-0.55 \\
(0.51)\end{array}$ & $\begin{array}{c}0.38 \\
(0.49)\end{array}$ & $\begin{array}{c}0.48 \\
(0.58)\end{array}$ & $\begin{array}{l}-1.24^{* *} \\
(0.54)\end{array}$ & $\begin{array}{c}0.53 \\
(0.52)\end{array}$ & $\begin{array}{c}0.41 \\
(0.51)\end{array}$ & $\begin{array}{c}0.59 \\
(0.51)\end{array}$ & $\begin{array}{c}0.37 \\
(0.36)\end{array}$ \\
\hline Election $_{s}$ & $\begin{array}{l}2.29^{* * *} \\
(0.66)\end{array}$ & $\begin{array}{l}1.32^{* *} \\
(0.63)\end{array}$ & $\begin{array}{l}1.28^{* *} \\
(0.68)\end{array}$ & $\begin{array}{c}0.57 \\
(0.64)\end{array}$ & $\begin{array}{l}-2.76^{* * *} \\
(0.61)\end{array}$ & $\begin{array}{l}-2.56^{\text {*** }} \\
(0.60)\end{array}$ & $\begin{array}{l}-0.54 \\
(0.61)\end{array}$ & $\begin{array}{l}-0.02 \\
(0.44)\end{array}$ \\
\hline Break Greens & - & - & - & - & $\begin{array}{c}1.25^{*} \\
(0.74)\end{array}$ & $\begin{array}{c}0.20 \\
(0.74)\end{array}$ & - & - \\
\hline Constant & $\begin{array}{l}-8.99^{* * *} \\
(1.86)\end{array}$ & $\begin{array}{l}-1.64 \\
(1.78)\end{array}$ & $\begin{array}{l}-6.96^{* * *} \\
(2.45)\end{array}$ & $\begin{array}{c}4.64^{*} \\
(2.30)\end{array}$ & $\begin{array}{l}4.16^{* * *} \\
(1.05)\end{array}$ & $\begin{array}{l}2.94^{* * *} \\
(1.04)\end{array}$ & $\begin{array}{c}1.28 \\
(1.05)\end{array}$ & $\begin{array}{c}0.71 \\
(0.74)\end{array}$ \\
\hline Adj. $R^{2}$ & 0.83 & 0.75 & 0.78 & 0.74 & 0.89 & 0.88 & 0.73 & 0.79 \\
\hline Obs. & \multicolumn{2}{|c|}{95} & \multicolumn{2}{|c|}{97} & \multicolumn{2}{|c|}{97} & \multicolumn{2}{|c|}{97} \\
\hline
\end{tabular}

Note: Standard errors robust to autocorrelation and heteroscedasticity in parentheses. $L$ stands for the standard mathematical lag operator, thus, it holds, for example, $L \operatorname{Poll}_{f}=\operatorname{Poll}_{f, t-1}$. A dash (-) signals that the variable is not part of the specific model. ${ }^{* *},{ }^{* *},{ }^{*}$ indicate statistical significance at the $1 \%, 5 \%$, and $10 \%$ level. 
Figure 8: Impulse responses for the direction $\mathrm{Poll}_{f} \rightarrow \mathrm{Poll}_{f}$
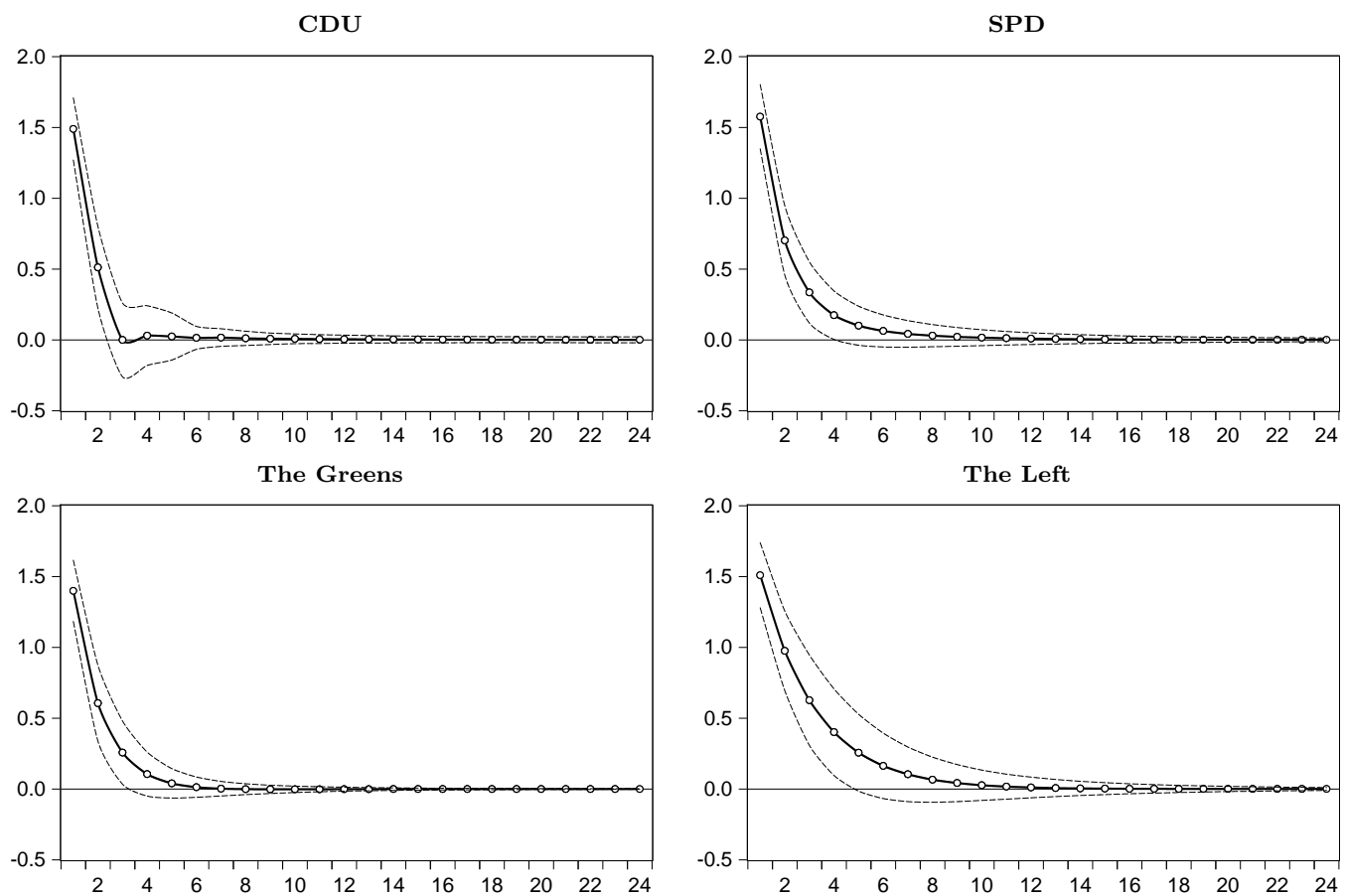

Note: Dotted lines present the impulse response functions up to 24 months. Dashed lines display bands of two standard errors.

Figure 9: Impulse responses for the direction $\mathrm{Poll}_{s} \rightarrow \mathrm{Poll}_{s}$
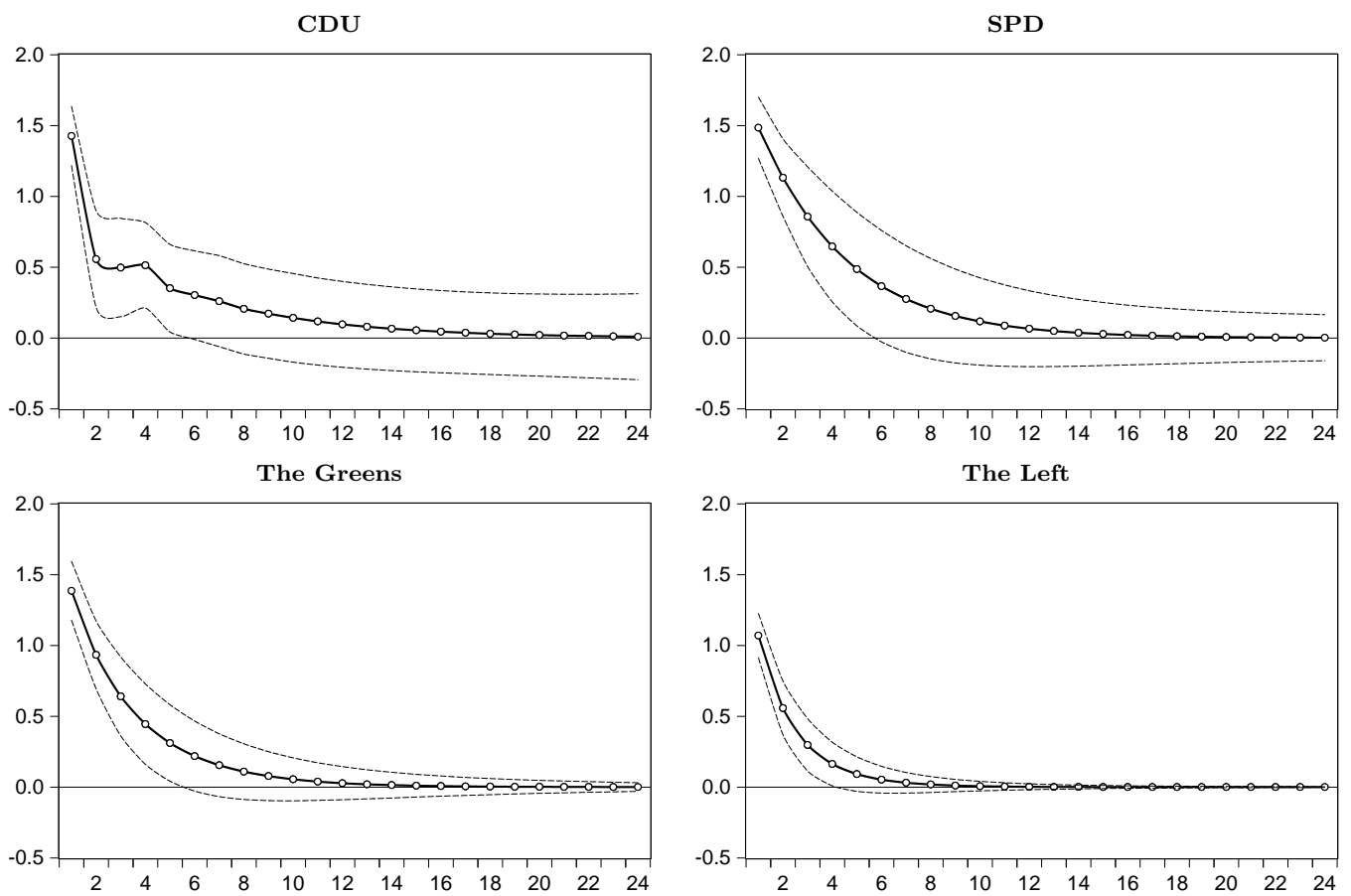

Note: Dotted lines present the impulse response functions up to 24 months. Dashed lines display bands of two standard errors. 
Figure 10: Impulse responses for the direction $\mathrm{Poll}_{f} \rightarrow \mathrm{Poll}_{s}$ with log-odds
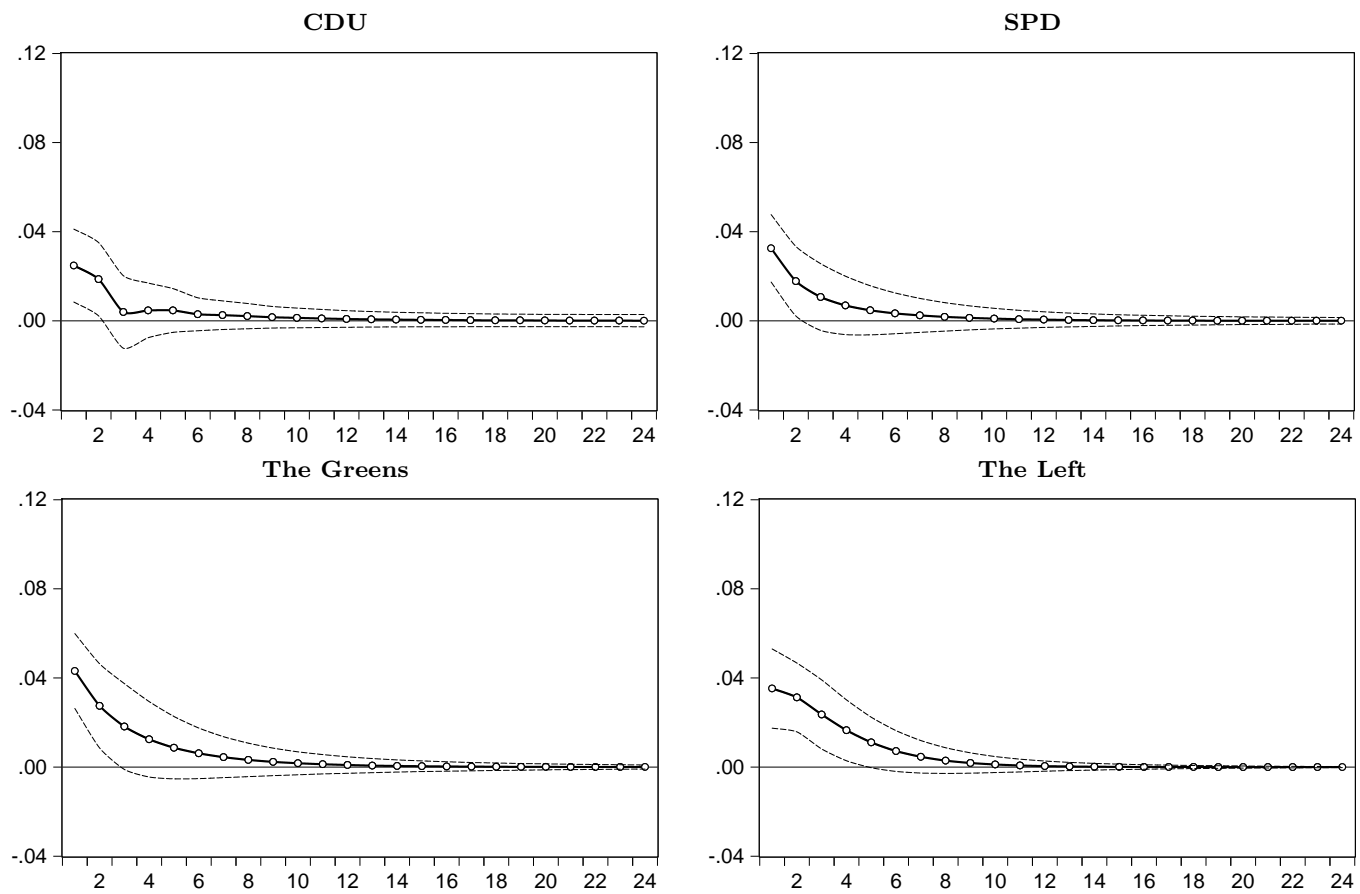

Note: Dotted lines present the impulse response functions up to 24 months. Dashed lines display bands of two standard errors.

Figure 11: Impulse responses for the direction $\mathrm{Poll}_{s} \rightarrow \mathrm{Poll}_{f}$ with log-odds
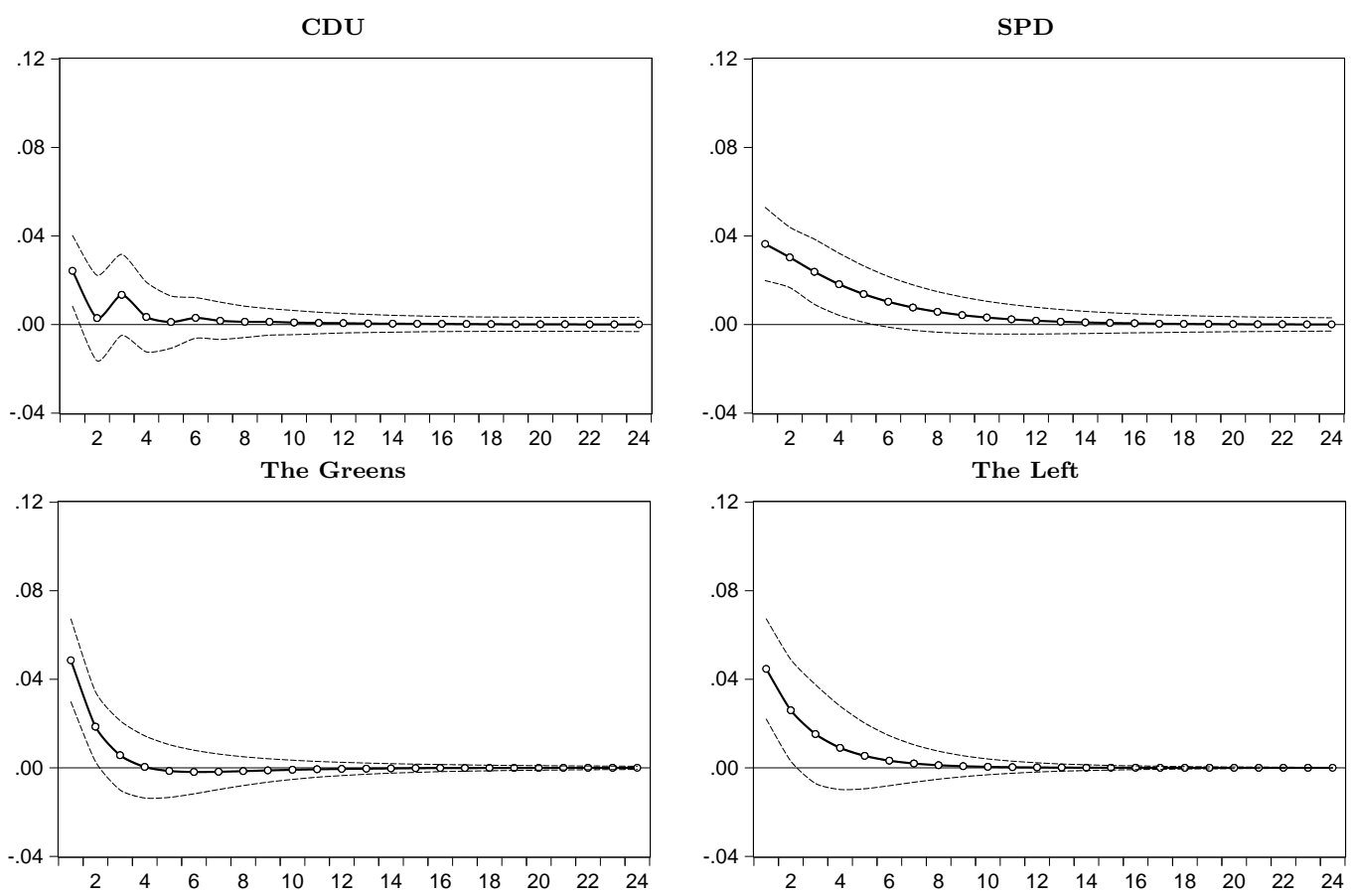

Note: Dotted lines present the impulse response functions up to 24 months. Dashed lines display bands of two standard errors. 
Figure 12: Impulse responses for the direction $\mathrm{Poll}_{f} \rightarrow \mathrm{Poll}_{s}$ without election dummies
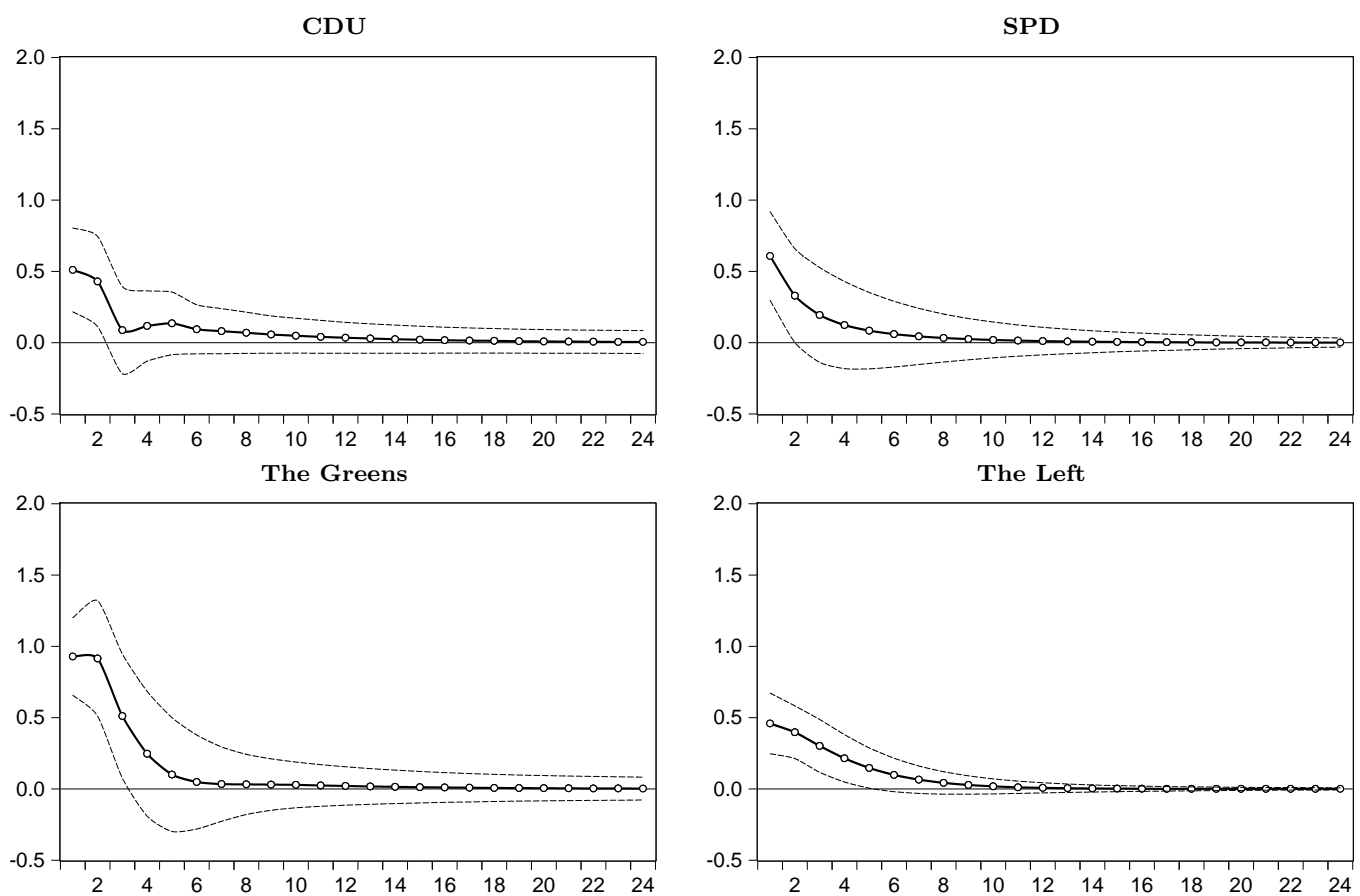

Note: Dotted lines present the impulse response functions up to 24 months. Dashed lines display bands of two standard errors.

Figure 13: Impulse responses for the direction $\mathrm{Poll}_{s} \rightarrow \mathrm{Poll}_{f}$ without election dummies
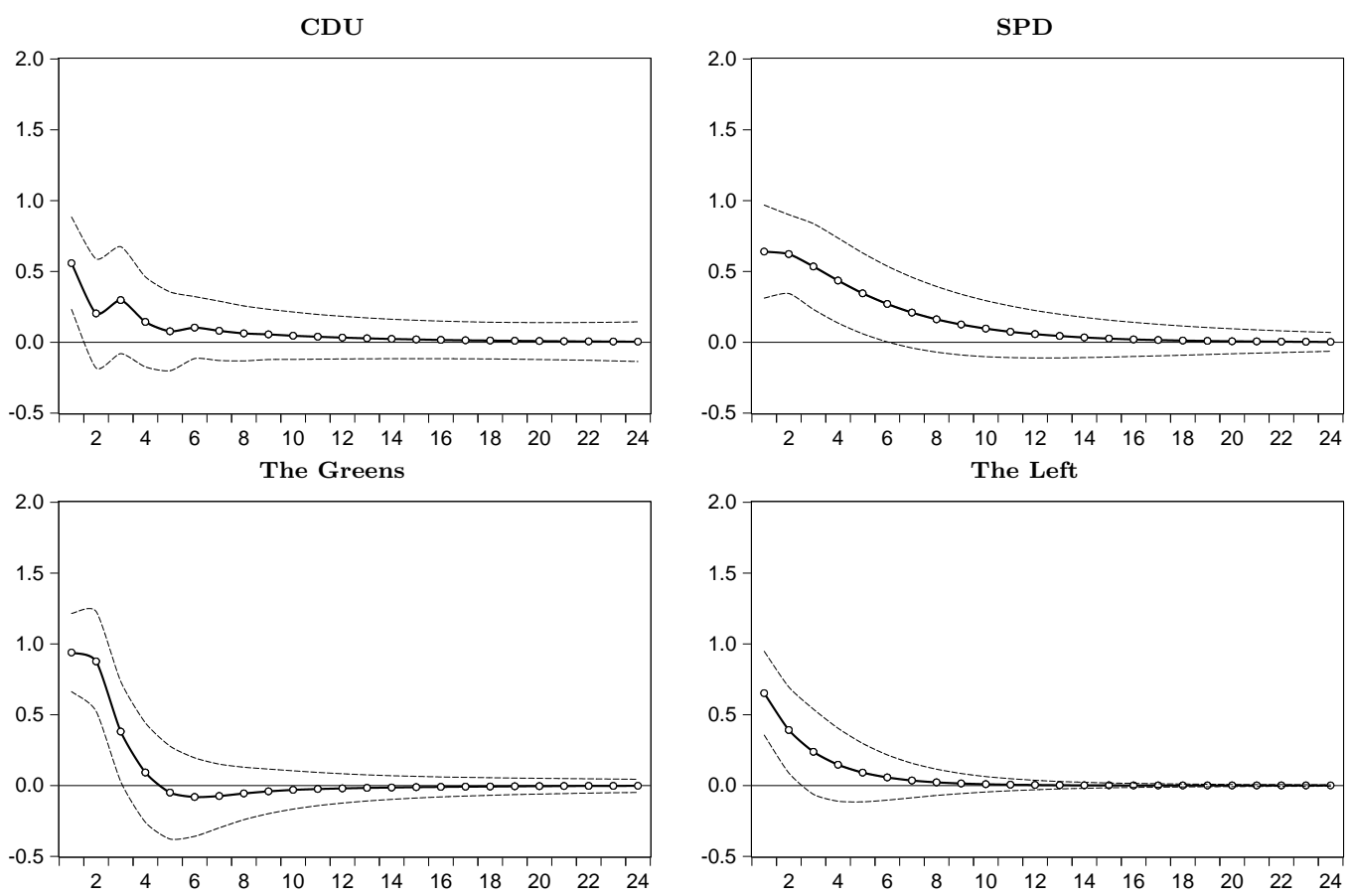

Note: Dotted lines present the impulse response functions up to 24 months. Dashed lines display bands of two standard errors. 